\title{
Excessive smartphone use symptoms associated with psychological distress as consequence of early phase COVID- 19 restrictions
}

\author{
Fatine Hadrya ${ }^{\mathrm{a}, \mathrm{b}}$, Faiçal El Hattimy ${ }^{\mathrm{b}}$, Btissame Zouini ${ }^{\mathrm{c}}$, Anis Sfendla ${ }^{\mathrm{c}, \mathrm{d}, \mathrm{e}}$ \\ a University Hassan First of Settat, Higher Institute of Health Sciences, Settat, Morocco \\ ${ }^{\mathrm{b}}$ Ibn Tofail University, Faculty of Sciences, Kenitra, Morocco \\ c Biology department, Faculty of Sciences, Abdelmalek Essaâdi University, Tetouan, Morocco \\ ${ }^{\mathrm{d}}$ High Institute of Nursing Professions and Health Techniques, Errachidia, Morocco \\ e Department of Biology, Faculty of Sciences and Techniques, Moulay Ismail University, Errachidia, Morocco
}

\begin{abstract}
Coronavirus disease (COVID-19) has been associated to various mental health problems and its consequences such as lock-down and social distancing were linked to various adaptations forms including increased smartphone usage. The purpose of the present study was to determine the prevalence of symptoms related to smartphone excessive use and to detect smartphone addiction symptoms related to general psychological distress. Participants were $(\mathrm{N}=260)$ surveyed during the first two weeks of lockdown measure. Online measures were introduced including sociodemographic background, Smartphone Addiction Scale Short Version (SAS-SV), and the Brief Symptoms Inventory (BSI). Among 260 Moroccan adults, the prevalence of excessive smartphone use was $48.4 \%$ (women: $59.6 \%$ / men: $40.4 \%$ ). Withdrawal, preoccupation, simultaneous presence of withdrawal and tolerance, with or without preoccupation, were significantly more observed among female users $(p=.019, p=.042, p=.023$ and $p=.003$; respectively). Comparing excessive smartphone users to non-excessive users, GSI and all BSI dimensions, showed higher significant difference in mean scores ( $r$ ranging from .15 to .31). SAS-SV total score was positively correlated with general distress (rho=.19, $p<.05$ ), depression (rho=.27, $p<.01$ ), and paranoid ideation (rho=.20, p<.05) in excessive smartphone users. Smartphone excessive use appears strongly associated with general distress, regardless of the circumstances. The results of this work provide sufficient evidence for the implementation of psychological interventions in general population during possible lock down measures or potential quarantine for potential next pandemic waves.
\end{abstract}

Keywords: Psychological distress, Excessive smartphone use, Addictive symptoms, Quarantine, COVID-19, Pandemic

\section{Introduction}

The coronavirus disease 2019 (COVID-19) represents a public health emergency. The broke out emerged in December 2019, in Wuhan, Hubei province, China. The disease speared afterwards worldwide, leading the World Health Organization (WHO) to classify the disease as pandemic on March 2020 [1]. This situation leads different government globally to establish response to crisis and suggested steps to limit population disease transmission. Among these recommendations, the limited access to public transportations [2], governmental, social, religious, and entertainment related facilities (e.g., gyms, museums, cinemas, sport stadiums) [3]. In addition, spatial distancing [4], remotely studying and working [5], and limitation of individual free movement and lockdown emerged as key solutions to reduce virus transmission.
Consequences of such measures resulted on establishing different life styles such as: reduction of daily life routines, somatic symptoms [6], fear [7], depressive symptoms [7], health anxiety [8], and higher psychological distress $[9,10]$. Moroccan population has also suffered from psychological distress during the pandemic, especially among those who had to leave for work, symptoms such as suspiciousness, uneasiness, discomfort during interpersonal interaction were reported [11].

In such environment, various forms of coping and entertainment strategies were noticed during the pandemic; increased consumption of pornography use [12], and online gaming [13], excessive social media use [14], and internet surfing [15] were noted and often used as a getaway solution from stressed situation and aversive

* Corresponding author: fatine.hadrya@uhp.ac.ma 
symptoms. It is important to acknowledge that significant increases in specific online activities can cause various problems and high risk of disordered use $[13,16]$. All of these activities are found in the smartphone, one of the today's advanced multifunctional technologies. Such all high-tech, smartphone can become an addiction. Indeed, it is globally observed that Moroccans, like other populations, have become more and more addicted and dependent on smartphones.

Problematic Smartphone Use (PSU) is considered an uncontrolled level of use leading to functional problems and negative consequences in everyday life [17]. PSU was previously related to mental health symptoms [18,19], neck and shoulder pain [20,21], along with hand dysfunction [22]. Only few studies investigated COVID19 anxiety, general anxiety and general depression symptoms on severity of PSU during COVID-19 outbreak where results revealed that COVID-19 anxiety correlated with severity of problematic smartphone use, depression and anxiety [23]. Right now, most of the authors' analysis have combined both genders. It remains of high importance to assess excessive smartphone use and its association to psychological distress by gender during early restrictive measures.

The short terms COVID-19 restrictions and associated measures have significantly increased negative emotions and psychological distress; therefore, the present paper taking into consideration the gender- has three aims: (a) to assess the prevalence and symptoms of smartphone excessive use, (b) to identify differences in psychological distress among those classified as excessive users and those not, and (c) to investigate the association of different psychological distress domains and smartphone use during the COVID-19 restrictions.

\section{Methods}

\subsection{Study design}

The present cross-sectional study was conducted among $(\mathrm{N}=260)$ and was particularly exploratory. Moroccan volunteers recruited through snowball sampling technique; participants were asked to participate and to recommend acquaintance to take part of the study. The study was implemented as an Arabic online anonymous survey. Data collection started one-week after restriction measures onset, the link was active to recruit participants for a period of 10 days.

\subsection{Instruments}

Participants answered several questions including sociodemographic questions and two surveys the Brief Symptoms Inventory (BSI) and Smartphone Addiction Scale-Short Version (SAS-SV).

\subsection{Background survey}

Age as continuous quantitative variable was studied. Gender was classified into "male" and "female". Education level was categorized onto "university", "high school", "secondary school", and "no qualifications"; employment on "with" and "without". Marital status was coded as "single", "married", "divorced", and "widow". Drinking, smoking and consuming drugs were registered on a binary answer (yes/no). The monitoring news on Covid-19 was recorder into "not following", "following once a day", "following two to three times a day" and "following instantly".

\subsection{Brief Symptoms Inventory (BSI)}

The BSI is a self-reported psychological distress instrument [24]. The inventory includes 53 items rated on a five-point Likert scale, grouped into nine psychiatric dimensions. These dimensions comprise somatization, obsessive-compulsivity, interpersonal sensitivity, depression, anxiety, hostility, phobic anxiety, paranoid ideation, and psychoticism. Moreover, the Global Severity Index (GSI) is calculated by adding the score of all dimensions and then divided by number of responses [25]. The GSI reflects general distress level. BSI was translated and adapted linguistically and culturally and had shown strong psychometric properties previously [26], reliability measured by Cronbach's alpha in the present study revealed a coefficient of .96 .

\subsection{Smartphone Addiction Scale-Short Version (SAS-SV)}

The SAS-SV is a short version of the original SAS (a selfdiagnosis scale perceiving smartphone addict) with 10 items. A previously translated and validated version by Sfendla and colleagues was used in the present study [27]. Within this sample, Cronbach's alpha coefficient revealed high reliability with a value of (.89). One or two items (calculating average of both) measured symptoms. Items were answered on a six-point Likert scale (1: "strongly disagree" to 6: "strongly agree"), and a rating of 4 or higher for each symptom means the strong presence of this specific symptom [28]. The scale covers six addictive symptoms: loss of control, disruption of family or schooling, disregard for consequences, withdrawal, preoccupation, and tolerance. Each item is related to SASSV symptom, except 4 items clusters: items 1 and 8 weighing loss of control, items 2 and 10 for disruptions, items 3 and 7 for disregard for consequences, and items 4 and 5 for withdrawal [29]. The sum of the six symptoms refers to SAS-SV score, ranging from 10 to 60 , where higher scores reflect higher addictive behavior to smartphone use [30]. The symptoms subjects have been calculated accordingly. For the identification of those with excessive smartphone use (the "Excessive smartphone users" group), the previously validated cutoff score of 31 was used for males and of 33 for females; therefore, those scoring lower scores than the proposed cut-off formed the group named as "non-excessive smartphone users". 


\subsection{Statistical analysis}

Statistical analyses were performed by IBM SPSS Statistics for Windows, Version 25.0. Armonk, NY: IBM Corp. Prevalence of SAS-SV symptoms was defined taking into consideration the cut-off of SAS-SV score by gender. Chi-square test $\left(\chi^{2}\right)$ was used to test the association between symptoms, symptoms combination and gender. The normality assumption was violated for SAS-SV symptoms and BSI dimensions (assessed by Kolmogorov-Smirnov test) to this end non parametric tests were performed. Group's comparisons were realized using Mann-Whitney U test. Spearman coefficient correlations rho were calculated to evaluate the association between SAS score and BSI dimensions, the follow rule of thumb was used $0.00-0.19$ "very weak; 0.20-0.39 "weak"; $0.40-0.59$ "moderate"; $0.60-0.79$ "strong"; $0.80-1.0$ "very strong". Effect sizes $(r)$ were calculated by dividing the $\mathrm{z}$ value by the square root of $\mathrm{N}$. Where $\mathrm{N}$ equals the total number of cases. Cohen's criteria for effect sizes were applied, where .1 equals a small effect, .3 a medium effect and .5 a large effect [31].

\subsection{Ethical consideration}

The ethical standards were in accordance with the Helsinki Declaration of 1964 . The study was performed after written consent submitted previously to participation in the study. The participants were informed that they were free to refuse to participate. The questionnaire was self-administered, avoiding direct contact interviewers participants and even between participants. Responses could not be traced back at individuals' level.

\section{Results}

\subsection{Participants}

The sample included 260 participants $(\mathrm{n}=148$ females, $\mathrm{n}=112$ males). The mean age was $32.85 \pm 10.77$ years old with an age range of 18 to 64 years. In this sample, $56.5 \%$ reported being single, $38.1 \%$ were married, $5 \%$ were divorced, and $.4 \%$ classified as widow. People with higher education represented $94.2 \%$, and with an employment were $36.2 \%$. Less than $5 \%$ smoke and consume alcohol and / or drugs. The news on the pandemic were followed by $94.6 \%$ of participants, from at least once a day $(28.5 \%)$ to instantly $(24.2 \%)$.

\subsection{Symptomatic subjects and SAS-SV addictive symptoms}

The prevalence of excessive smartphone use was $48.4 \%$ (109/225). Among the excessive smartphone users and based on the defined specific gender cut-offs', the prevalence of female's users was 59.6\% (65/109), while for male users was $40.4 \%$ (44/109).

Table 1. Symptom analysis in SAS-SV among Moroccan male and female excessive smartphone users $(n=109)$

\begin{tabular}{|c|c|c|c|c|c|}
\hline SSC & n. S (\%) & $\begin{array}{c}\text { n. F } \\
(n=65) \\
(\%)\end{array}$ & $\begin{array}{c}\text { n. M } \\
(n=44) \\
(\%)\end{array}$ & 2 & $p$ \\
\hline 1 & $68(62.4)$ & $41(63.1)$ & $27(61.4)$ & .03 & .856 \\
\hline 2. & $62(56.9)$ & $39(60.0)$ & $23(52.3)$ & .64 & .424 \\
\hline 3. & $66(60.5)$ & 40 (61.5) & $26(59.1)$ & .07 & .797 \\
\hline 4. & $52(47.7)$ & $37(56.9)$ & $15(34.1)$ & 5.48 & .019 \\
\hline 5. & 74 (67.9) & $49(75.4)$ & $25(56.8)$ & 4.15 & .042 \\
\hline 6. & $100(91.7)$ & $59(90.8)$ & $41(93.2)$ & .01 & .925 \\
\hline $4+6$ & 49 (44.9) & $35(53.8)$ & $14(31.8)$ & 5.14 & .023 \\
\hline $4+6+1$ & 37 (33.9) & $26(40.0)$ & $11(25.0)$ & 2.63 & .105 \\
\hline $4+6+2$ & $35(32.1)$ & $24(36.9)$ & $11(25.0)$ & 1.71 & .191 \\
\hline $4+6+3$ & $36(33.0)$ & $24(36.9)$ & $12(27.3)$ & 1.10 & .293 \\
\hline $4+6+5$ & $43(39.4)$ & $33(50.8)$ & $10(22.7)$ & 8.64 & .003 \\
\hline Two to & $79(72.5)$ & $45(69.2)$ & $34(77.3)$ & .85 & .356 \\
\hline $\begin{array}{l}\text { five ss. } \\
\text { Four to } \\
\text { six ss. }\end{array}$ & $61(56.0)$ & $41(63.1)$ & $20(45.4)$ & 3.31 & .069 \\
\hline
\end{tabular}

SSC: Symptoms and symptom combinations (1. Loss of control; 2. Disruption; 3. Disregard; 4. Withdrawal; 5. Preoccupation; 6. Tolerance; ss.: symptoms simultaneously); S: Subjects; F: Females; M: Males; Chi-square test or Yates correction, if the validity conditions are violated; p: Signification

Among excessive smartphone users, tolerance had the highest frequency $(91.7 \%)$. Regarding the combined symptoms, withdrawal and tolerance were simultaneously present with a frequency of $44.9 \%$, and in the presence of the preoccupation with a frequency of $39.4 \%$. The simultaneous presence of more than four symptoms was observed in approximately $56.0 \%$ of the excessive smartphone users. In comparison with male users, withdrawal, preoccupation, simultaneous presence of withdrawal and tolerance, with or without preoccupation, were significantly more often among female users $(\mathrm{p}=.019, \mathrm{p}=.042, \mathrm{p}=.023$ and $\mathrm{p}=.003$; respectively).

\subsection{Psychological distress comparison among smartphone user groups}

GSI and all BSI dimensions revealed higher significant difference in mean scores when comparing excessive smartphone users to non-excessive users. In details, significant higher obsessive-compulsive mean score was reported among excessive users $(\mathrm{M}=1.63, \mathrm{SD}=.79$, $\mathrm{N}=109)$ when compared to non-excessive users $(\mathrm{M}=1.18$, $\mathrm{SD}=.66, \mathrm{~N}=116 ; \mathrm{Z}=-4.61, \mathrm{p}<.001, \mathrm{r}=.31$ ). Similarly, higher means among excessive smartphone users were reported for GSI, anxiety, depression, interpersonal sensitivity, psychoticism, and phobic anxiety. Table 2 displays psychological distress group's comparison between excessive and non-excessive smartphone user. 
Table 2. Differences in psychological distress based on excessive smartphone use

\begin{tabular}{|c|c|c|c|c|c|c|c|}
\hline \multirow{2}{*}{ BSI domains } & \multicolumn{2}{|c|}{$\begin{array}{l}\text { Excessive smartphone users } \\
(\mathrm{n}=109)\end{array}$} & \multicolumn{2}{|c|}{$\begin{array}{c}\text { Non-excessive smartphone } \\
\text { users }(\mathrm{n}=116)\end{array}$} & \multirow{2}{*}{$P$ value } & \multirow{2}{*}{$Z$ score } & \multirow[t]{2}{*}{$r$} \\
\hline & Mean & SD & Mean & SD & & & \\
\hline GSI & 1.18 & .61 & .85 & .49 & .000 & -4.000 & .26 \\
\hline Anxiety & 1.27 & .71 & .87 & .68 & .000 & -4.340 & .28 \\
\hline Depression & 1.06 & .74 & .71 & .52 & .000 & -3.570 & .23 \\
\hline Interpersonal Sensitivity & 1.20 & .80 & .83 & .70 & .000 & -3.503 & .23 \\
\hline Hostility & .94 & .60 & .74 & .55 & .011 & -2.539 & .16 \\
\hline Obsessive compulsive & 1.63 & .79 & 1.18 & .66 & .000 & -4.610 & .31 \\
\hline Psychoticism & 1.00 & .76 & .70 & .58 & .004 & -2.850 & .20 \\
\hline Paranoid Ideation & 1.22 & .71 & 1.01 & .73 & .027 & -2.207 & .15 \\
\hline Phobic Anxiety & 1.20 & .80 & .76 & .62 & .000 & -4.185 & .28 \\
\hline Somatization & .93 & .64 & .71 & .52 & .012 & -2.519 & .17 \\
\hline
\end{tabular}

\subsection{Correlations between SAS-SV total score and BSI dimensions in excessive smartphone users}

The association between SAS-SV total score and the different dimensions of BSI among excessive smartphone male and female users is detailed in table 3. SAS-SV total score showed a significant positive correlation with GSI $(\mathrm{rho}=.19, \mathrm{p}<.05)$, depression $(\mathrm{rho}=.27, \mathrm{p}<.01)$ and paranoid ideation $(\mathrm{rho}=.20, \mathrm{p}<.05)$.

Table 3. Correlations between SAS-SV total score in excessive smartphone users and BSI dimensions

\begin{tabular}{lccc}
\hline \multirow{2}{*}{ BSI domains } & \multicolumn{3}{c}{ SAS SV total score } \\
\cline { 2 - 4 } & $\begin{array}{c}\text { Excessive } \\
\text { smartphone } \\
\text { users } \\
(\mathrm{n}=109) \\
\text { rho }(p- \\
\text { value })\end{array}$ & $\begin{array}{c}\text { Excessive } \\
\text { smartphone } \\
\text { in female } \\
\text { users }(\mathrm{n}=65)\end{array}$ & $\begin{array}{c}\text { Excessive } \\
\text { rhartphone } \\
\text { in male } \\
\text { users }(\mathrm{n}=44) \\
\text { rho }(p- \\
\text { value })\end{array}$ \\
\hline GSI & $.195(.042)$ & $.303(.014)$ & $-.089(.564)$ \\
Anxiety & $.112(.245)$ & $.253(.042)$ & $-.208(.175)$ \\
Depression & $.266(.005)$ & $.405(.001)$ & $-.007(.965)$ \\
IS & $.185(.054)$ & $.212(.090)$ & $-.002(.991)$ \\
Hostility & $.089(.359)$ & $.123(.328)$ & $.002(.989)$ \\
OC & $.186(.053)$ & $.348(.005)$ & $-.176(.252)$ \\
Psychoticism & $.179(.063)$ & $.252(.043)$ & $-.005(.975)$ \\
PI & $.200(.037)$ & $.305(.013)$ & $.018(.907)$ \\
PA & $.158(.102)$ & $.238(.057)$ & $-.079(.611)$ \\
Somatization & $.063(.517)$ & $.145(.248)$ & $-.191(.215)$ \\
\hline
\end{tabular}

IS: Interpersonal sensitivity; OC: Obsessive compulsive; PI: Paranoid ideation; PA: Phobic anxiety

Among the female users, SAS-SV total score was positively correlated with GSI $(\mathrm{rho}=.30, \mathrm{p}<.05)$, and six dimensions (anxiety $(\mathrm{rho}=.25, \mathrm{p}<.05)$; depression $(\mathrm{rho}=.40, \mathrm{p}<.01)$; obsessive compulsive disorders $(\mathrm{rho}=.35, \mathrm{p}<.01) ;$ psychoticism $(\mathrm{rho}=.25, \mathrm{p}<.05)$; and paranoid ideation $(\mathrm{rho}=.30, \mathrm{p}<.05)$. Among the male users, SAS-SV total score did not reveal any association with BSI dimensions $(\mathrm{p}>.05)$.

\section{Discussion}

Findings in the present study demonstrated that higher frequency of tolerance was observed among excessive smartphone users; while withdrawal, preoccupation, simultaneous presence of withdrawal and tolerance, with or without preoccupation were significantly more prevalent among female. Excessive smartphone users scored significantly higher in the majority of psychological distress aspects; although, significant relationship was reported between excessive smartphone users with general distress, depression, and paranoid ideation; whilst, more associations were noted with female excessive users' group.

\subsection{Prevalence of Excessive Smartphone Use}

The present study - to our knowledge - is among the first of its kind that assessed the prevalence of problematic smartphone use among Moroccan general population and adds important learnings from early COVID-19 pandemic stages. The prevalence reported in the present study are higher than those reported previously in a systematic review by Sohn et al., (2021) reporting that the majority of studies have found a prevalence of PSU between 10 and $30 \%$ among children and young people. In a like manner, the results from Smetaniuk, (2014) indicates that 10 to $25 \%$ of a student and non-student samples exhibited problematic cell phone usage. However, most of the studies on the prevalence of PSU focused on young adults and prior COVID-19 pandemic $[33,35]$. Thus, our study shows that the level of PSU is substantially higher during the early stages of COVID-19 pandemic than before this period and support the fact that females are more likely to present PSU. 


\subsection{Symptomology related to Excessive Smartphone Use}

Excessive smartphone users reported higher tolerance that refers to marked increase in smartphone use required achieving satisfaction, the present study was conducted during early phase of COVID-19 restriction where distant education and several professionals adopted remote work, that could also explain the relatively high levels of the SAS-SV score and consequently the presence of symptoms related to the PSU. According to Duan et al., (2020) the pandemic and social isolation were more likely associated with smartphone and internet addiction, which can enhance tolerance to achieve satisfaction. Accordingly, self-isolation promotes more use of smartphones by people while staying home; it was previously supported that $70 \%$ of internet users were using their phone as direct consequence of pandemic lockdown [37]. Moreover, some studies [38,39] support the fact that university students with low self-control tend to respond immediately after getting a notification; which could result in a social isolation and low degree of integration. Thus, this could be shaped as a form of withdrawal and preoccupation, which are manifested, by a dysphoric mood, anxiety, irritability and boredom after several days without smartphone activity. Similarly, gender symptomology revealed that female participants reported more withdrawal, preoccupation, and tolerance symptoms combined; female gender predominance was noticed among undergraduate student that participate in the study of Wilmer \& Chein, (2016) where it was stated that heavier engagement in mobile devices was correlated to greater inclination toward impulsive behavior (i.e., weaker impulse control). However, it was previously declared that male gender is more prone to impulse control disorders yet this association was not straight forward and depends on the tasks and subject samples [40].

\subsection{Excessive Smartphone Use and psychological distress}

During the outbreak, distancing from friends and relatives in addition to continued excessive use of smartphone despite knowledge of having a persistent or recurrent physical or psychological problems likely to have been caused or aggravated by smartphone use, both contributed to social alienation and escapism [41]. Smartphone overusing pattern refers to a tendency to check unceasingly notifications, such pattern can induce "reassurance seeking" pathway which includes symptoms such as depression, and anxiety [42]. Several studies revealed that depression severity and anxiety severity were consistently related to problem smartphone use [4351]. These results are consistent with the associations found in the present study and support the association between PSU and psychological distress. PSU has always been associated with measures of poor mental health, including depression, anxiety, stress, poor quality of sleep, and daily functional impairment demonstrated by low education [23,34]; this association - could be enhanced more - within a context of pandemic and quarantine.

In line with other research, the suggested findings also revealed a strong association with obsessive compulsive and paranoid ideation dimensions. For instance, a prospective cohort study evaluated the effect of COVID19 pandemic on obsessive-compulsive symptoms found that fear of COVID-19 was associated with increased symptoms of obsessive-compulsive. This could imply that quarantine environment combined with fear and/ or anxiety might be involved in obsessive-compulsive symptoms and that fear of negative events might play a role in the etiology of obsessive-compulsive symptoms [52].

Furthermore, high COVID-19 related social media consumption can lead to (mis) information overload, new uncertainty, and therefore increase levels of distress, which in turn can impact mental health [53]. Research suggests these media sources are often the cause of increased stress that contributes to major psychological issues associated with receiving conflicting messages related to COVID-19 [53,54]. These information-seeking behaviors through traditional and social media can lead to periods of uncertainty thus affecting mental state and triggering symptoms related to anxiety and depression [55-58].

This offers further support to the finding in the present study of excessive smartphone use strongly correlating with symptoms of obsessive compulsion during early stages of COVID-19 pandemic. The prevalence of possible obsessive-compulsive symptoms was much higher at the beginning of the pandemic compared to later, suggesting that possible obsessive-compulsive symptoms was induced in the early stage of the COVID-19 pandemic [52]. The present data assessment was also initiated at the first weeks of the pandemic which could explain the high association of obsessive-compulsive symptoms.

Likewise, Castellini et al., (2021) and Jiang (2020) reported that regardless of smartphone use, paranoid ideation was associated to COVID-19 pandemic context. Nonetheless the coronavirus epidemic caused social isolation is more likely associated with smartphone excessive use, which further strengthen depressive and anxiety symptoms in adolescents [36].

Several studies have reported the existence of a set of factors behind the increase in psychological distress, including gender (for women) [61-71], COVID-19 contraction risk (poorer health, contact with COVID-19 patients) [61,64-67,72-74], social isolation [61,75,76], and the time spent watching COVID-19 related news $[66,77]$.

Female and male use smartphone in different manners [78], what supports our results. Nevertheless, in a recent study of Elhai et al., (2020) realized on participants from Canada and the US, greater severity of PSU appears in men than women, while much previous work has revealed an inverse pattern to Elhai et al., (2020b) similar to ours. 
During the COVID-19 pandemic, women more often worked as frontline workers in the health and food industry, while men more often worked remotely from home [81]. As a result, men may have had better access and more time spent on smartphones at home. In contrast, a study on PSU among the adult population of Bangladesh [82] and Chinese adults [80] revealed that women and men have the same level of addiction.

\subsection{Limitations and future research directions}

This study adopted the method of convenient sampling combined with snowball sampling. This may cause partial bias in the samples. The present sample was not a national based representative sample. The participants represent a self-selected group. Generalizability of the results should be taken with caution. A large-scale cohort studies are required to assess the long-term psychological health effect on general population. Other potential factors may be behind the increase in psychological distress were not isolated in the analysis. In this way, it's possible to gain more comprehensive understanding of the negative impacts of public mental health during early stage of restrictions, in order to set urgent psychological interventions. This study gives a prospect of what it was like at early phase of pandemic. The research group motivation was to inspect the differential effects on adults depending on the level of disruption to identify which group might need the most help for policymakers and potential caregivers. Obtaining enough information about the adverse effects of early-stage restrictions during the pandemic was crucial because a study realized months later would have been subject to the limitations of substantial recall bias.

\section{Conclusion}

This study revealed that smartphone addiction use appears strongly associated with general distress with differences between female and male users. The population and psychotherapists need to consider new approaches to smartphone use at early stages of pandemic and could be applied to next waves related restriction. Future directions in mental public health that improve response to major pandemic events must be taken more seriously to prevent severe psychological and social problems.

\section{References}

1. World Health Organization. Novel Coronavirus(2019NCoV) Situation Report-93. 14 (2020)

2. J. Park. Cureus 12,4 (2020)

3. S. Yezli, A. Khan. Travel med. Infect. Dis. 101692 (2020)

4. T. Abel, D. McQueen. Int. J. Public Health, 65, 3, 231 (2020)

5. K. Iyengar, G.K. Upadhyaya, R. Vaishya, V. Jain. Diabetes Metab. Syndr.: Clin. Res. Rev. 14, 5, 733-737 (2020)
6. S. Liu, Y. Liu, Y. Liu. Psychiatry Res. 289, 113070 (2020)

7. W. Tang, T. Hu, B. Hu, C. Jin, G. Wang, C. Xie, S. Chen, J. Xu. Affect. Disord. 274, 1-7 (2020).

8. S.M. Jungmann, M. Witthöft. J. Anxiety Disord. 73, 102239 (2020)

9. S.K. Brooks, R.K. Webster, L.E. Smith, L. Woodland, S. Wessely, N. Greenberg, G.J. Rubin. Lancet. 395, 10227, 912-920 (2020)

10. C. Wang, K. Li, M. Kim, S. Lee, D.C. Seo. Addict. Behav. 90, 112-118 (2018)

11. A. Sfendla, F. Hadrya. Health Secur. 18, 6, 444-453 (2020)

12. G. Mestre-Bach, G.R. Blycker, M.N. Potenza. J. Behav. Addict. 19-21 (2020)

13. D.L. King, P.H. Delfabbro, J. Billieux, M.N. Potenza. J. behav. addict. 9, 2, 184-186 (2020)

14. J. Mander. Coronavirus: How Consumers Are Actually Re-Acting. 2020. https://blog.globalwebindex.com/trends/coronavirusand-consumers/. Accessed June 11, 2020

15. A. Slisco. Americans Binged on Video Games, Shrugged off Social Media as Pandemic Restrictions Kicked In: Verizon Says, 2020. https://www.newsweek.com/instead-working-homemost-americans-are-using-self-isolation-catch-videogames-1493129. Accessed June 11, 2020

16. N.A. Fineberg, Z. Demetrovics, D.J. Stein, K. Ioannidis, M.N. Potenza, E. Grünblatt, M. Brand, J. Billieux, L. Carmi, D.L. King, J.E. Grant, M. Yücel, B. Dell'Osso, H.J. Rumpf, N. Hall, E. Hollander, A. Goudriaan, J. Menchon, J. Zohar, J. Burkauskas, G. Martinotti, M. Van Ameringen, O. Corazza, S. Pallanti, S.R. Chamberlain. Eur. Neuropsychopharmacol. 28, 11, 1232-1246 (2018)

17. J. Billieux, A. Schimmenti, Y. Khazaal, P. Maurage, A. Heeren. J. behav. addict. 4, 3, 119-123 (2015)

18. J.D. Elhai, R.D. Dvorak, J.C. Levine, B.J. Hall. J. Affect. disord. 207, 251-259 (2017)

19. J. Yang, X. Fu, X. Liao, Y. Li. Psychiatry Res. 284, $112686(2020)$

20. Z. Shan, G. Deng, J. Li, Y. Li, Y. Zhang, Q. Zhao. PloS One. 8, 10, e 78109 (2013)

21. S. Namwongsa, R. Puntumetakul, M.S. Neubert, R. Boucaut. Ergonomics. 62, 12, 1524-1533 (2019)

22. E.E. İNal, K. Demİrcİ, A. Çetİntürk, M. Akgönül, S. Savaş. Muscle Nerve. 52, 2, 183-188 (2015)

23. J.D. Elhai, H. Yang, D. McKay, G.J.G. Asmundson. J. Affect. Disord. 274, 576-582 (2020)

24. L.R. Derogatis. Psychol. Med. 13, 3, 595-605 (1983)

25. L.R. Derogatis, K.L. Savitz. The $S C L-90-R$ and Brief Symptom Inventory (BSI) in primary care. In: Handbook of Psychological Assessment in Primary Care Settings. Mahwah, NJ, US: Lawrence Erlbaum Associates Publishers. 297-334 (2000)

26. B. Zouini, A. Sfendla, B. Hedman Ahlström, M. Senhaji, N. Kerekes. Ann. Gen. Psychiatry. 18, 1, 27 (2019)

27. A. Sfendla, M. Laita, B. Nejjar, Z. Souirti, A.A.O. Touhami, M. Senhaji. Cyberpsychol. Behav. Soc. Netw. 21, 5, 325-332 (2018)

28. J. Phillips, L. Saling, A. Blaszczynski. Psychology of Mobile Phone Use and Misuse. In A. C. Harper, \& R. V. Buress (Eds.), Mobile Telephones: Networks, Applications and Performance (6 ed., pp. 191-210). Nova Science Publishers (2008)

29. O. Lopez-Fernandez. Addict. Behav. 64, 275-280 (2017)

30. M. Kwon, D.J. Kim, H. Cho, S. Yang. PLoS One. 8, 12, 
1-7 (2013)

31. J. Cohen. Statistical Power Analysis for the Behavioral Sciences (1988)

32. S.Y. Sohn, P. Rees, B. Wildridge, N.J. Kalk, B. Carter. BMC Psychiatry. 21, 1, 12888 (2021)

33. P. Smetaniuk. J. Behav. Addict. 3, 1, 41-53 (2014)

34. S. Sohn, P. Rees, B. Wildridge, N.J. Kalk, B. Carter. BMC psychiatry. 19, 1, 397 (2019)

35. P. Smetaniuk. J. Behav. Addict. 3, 1, 41-53 (2014)

36. L. Duan, X. Shao, Y. Wang, Y. Huang, J. Miao, X. Yang, G. Zhu. Affect. Disord. 275, 112-118 (2020)

37. K. Sebire. The coronavirus lockdown is forcing us to view "screen time" differently. That's a good thing. https://theconversation.com/the-coronaviruslockdown-is-forcing-us-to-view-screen-timedifferently-thats-a-good-thing-135641. Published 2020. Accessed February 24, 2021

38. S. Berger, A.M. Wyss, D. Knoch. Comput. Hum. Behav. 86, 45-51 (2018)

39. H.H. Wilmer, J.M. Chein. Psychon. Bull. Rev. 23, 5, 1607-1614 (2016)

40. J. Weafer, H. de Wit. Addict. Behav. 39, 11, 1573-1579 (2014)

41. B. Fernandes, U.N. Biswas, R. Tan-Mansukhani, A. Vallejo, C. Essau. Rev. Psicol. Clín. Niños Adolesc. 7, 3, 59-65 (2020)

42. Z.A. Ratan, S.B. Zaman, S.M.S. Islam, H. Hosseinzadeh. Health Policy Technol. 10, 1, 21-22 (2021)

43. J.D. Elhai, R.D. Dvorak, J.C. Levine, B.J. Hall. J. Affect. Disord. 207, 251-259 (2017)

44. B. Chen, F. Liu, S. Ding, X. Ying, L. Wang, Y. Wen. BMC Psychiatry. 17, 1, 1-9 (2017)

45. J. Long, T.Q. Liu, Y.H. Liao, C. Qi, H.Y. He, S.B. Chen, J. Billieux. BMC Psychiatry. 16, 1, 1-12 (2016)

46. Y.S. Kwon, K.S. Paek. Indian J. Sci. Technol. 9, 41 (2016)

47. K. Demirci, M. Akgönül, A. Akpinar. J. Behav. Addict. 4, 2, 85-92 (2015)

48. L. Chen, Z. Yan, W. Tang, F. Yang, X. Xie, J. He. Comput. Hum. Behav. 55, 856-866 (2016)

49. S. Tao, X. Wu, Y. Zhang, S. Zhang, S. Tong, F. Tao. Int. J. Environ. Res. Public Health. 14, 2, 1-10 (2017)

50. J. Tavakolizadeh, A. Atarodi, S. Ahmadpour, A. Pourgheisar. Razavi Int. J. Med. 2, 1 (2014)

51. M. Eyvazlou, E. Zarei, A. Rahimi, M. Abazari. Chronobiol. Int. 33, 3, 293-300 (2016)

52. G. Ji, W. Wei, K.C. Yue, H. Li, L.J. Shi, J.D. Ma, C.Y. He, S.S. Zhou, Z. Zhao, T. Lou, J. Cheng, S.C. Yang, X.Z. Hu. J. Med. Internet res. 22, 9, e21915 (2020)

53. D.R. Garfin, R.C. Silver, E.A. Holman. Health Psychol. 39, 5, 355-357 (2020)

54. B. Pfefferbaum, C.S. North. N. Engl. J. Med. 383, 6, 510-512 (2020)

55. A.H. Ebrahim, Z.Q. Saif, M. Buheji, N. Al Basri, F.A. Al-Husaini, H. Jahrami. OSP J. Health Car. Med. 1. HCM-1-105 (2020)

56. M. Chao, D. Xue, T. Liu, H. Yang, B.J. Hall. J. Anxiety Disord. 74, 102248 (2020)

57. A. Moreno, C. Fuentes-Lara, C. Navarro. Prof. de la Inf. 29, 4, 1-16 (2020)

58. L. Li, Q. Zhang, X. Wang, J. Zhang, T. Wang, T. Gao, W. Duan, K. Tsoi, F. Wang. IEEE Trans. Comput. Soc. Syst. 7, 2, 556-562 (2020)

59. G. Castellini, E. Rossi, E. Cassioli, G. Sanfilippo, M. Innocenti, V. Gironi, C. Silvestri, F. Voller, V. Ricca. J. psychosom. res. 141, 110328 (2020).

60. R. Jiang. Child. Youth Serv. Rev. 119, 105494 (2020)

61. L. Lei, X. Huang, S. Zhang, J. Yang, L. Yang, M. Xu.
Med. Sci. Mon. Int. Med. J. Exp. Clin. Res. 26, e924609-e924609 (2020)

62. W.R. Zhang, K. Wang, L. Yin, W.R. Zhang, K. Wang, L. Yin, W.F. Zhao, Q. Xue, M. Peng, B.Q. Min, Q. Tian, H.X. Leng, J.L. Du, H. Chang, Y. Yang, W. Li, F.F. Shangguan, T.Y. Yan, H.Q. Dong, Y. Han, Y.P. Wang, F. Cosci, H.X. Wang. Psychother. Psychosom. 89, 4, 242-250 (2020)

63. N. Liu, F. Zhang, C. Wei, Y. Jia, Z. Shang, L. Sun, L. Wu, Z. Sun, Y. Zhou, Y. Wang, W. Liu. Psychiatry Res. 287, 112921 (2020)

64. C. Wang, R. Pan, X. Wan, Y. Tan, L. Xu, C.S. Ho, R.C. Ho. Int. J. Environ. Res. Public Health. 17, 5 (2020)

65. C. Mazza, E. Ricci, S. Biondi, M. Colasanti, S. Ferracuti, C. Napoli, P. Roma. Int. J. Environ. Res. Public Health. 17, 9, 3165 (2020)

66. A. Moghanibashi-Mansourieh. Asian J. Psychiatr. 51, 102076 (2020)

67. S. Özdin, Ş. Bayrak Özdin. Int. J. Soc. Psychiatr. (2020)

68. A.A. Jahanshahi, M.M. Dinani, A.N. Madavani, J. Li, S.X. Zhang. Brain Behav. Immun. 87, 124-125 (2020)

69. L. Moccia, D. Janiri, M. Pepe, L. Dattoli, M. Molinaro, V. De Martin, D. Chieffo, L. Janiri, A. Fiorillo, G. Sani, M. Di Nicola. Brain Behav. Immun. 87, 75-79 (2020)

70. P. Voitsidis, I. Gliatas, V. Bairachtari, K. Papadopoulou, G. Papageorgiou, E. Parlapani, M. Syngelakis, V. Holeva, I. Diakogiannis. Psychiatry Research. 289, 113076 (2020)

71. J. Qiu, B. Shen, M. Zhao, Z. Wang, B. Xie, Y. Xu. General Psychiatry. 33, 2, 1-4 (2020)

72. J. Zhang, H. Lu, H. Zeng, S. Zhang, Q. Du, T. Jiang, B. Du. Brain Behav. Immun. 87,49-50 (2020)

73. M.Y. Ni, L. Yang, C.M.C. Leung, N. Li, X.I. Yao, Y. Wang, G.M. Leung, B.J. Cowling, Q. Liao. JMIR Ment. Health. 7, 5, e19009 (2020)

74. M. Shacham, Y. Hamama-Raz, R. Kolerman, O Mijiritsky, M. Ben-Ezra, E. Mijiritsky. Int. J. Environ. Res. Public Health. 17, 8 (2020)

75. Q. Guo, Y. Zheng, J. Shi, J. Wang, G. Li, C. Li, J.A Fromson, Y. Xu, X. Liu, H. Xu, T. Zhang, Y. Lu, X. Chen, H. Hu, Y. Tang, S. Yang, H. Zhou, X. Wang, H. Chen, Z. Wang, Z. Yang. Brain Behav. Immun. 88, $17-$ 27 (2020)

76. F. Durankuş, E. Aksu. J. Matern. Fetal Neonatal Med. 18, 1-7 (2020)

77. J. Li, Z. Yang, H. Qiu, Y. Wang, L. Jian, J. Ji, K. Li. World Psychiatry. 19, 2, 249-250 (2020)

78. I. Andone, K. Błaszkiewicz, M. Eibes, B. Trendafilov, C. Montag, A. Markowetz. How age and gender affect smartphone usage. In: Proceedings of the UbiComp '16. Association for Computing Machinery, New York, NY, USA, 9-12 (2016)

79. J.D. Elhai, D. McKay, H. Yang, C. Minaya, C. Montag, G.J.G. Asmundson. Hum. Behav. Emerg. Technol. 10.1002/hbe2.227 (2020)

80. J.D. Elhai, H. Yang, D. McKay, G.J.G. Asmundson. J. Affect. Disord. 274, 576-582 (2020)

81. C. Wenham, J. Smith, R. Morgan. Lancet. 395, 10227, 846-848 (2020)

82. M.S. Islam, M.S.H. Sujan, R. Tasnim, M.Z. Ferdous, J Masud, S. Kundu, A. Mosaddek, M. Choudhuri, K. Kircaburun, M.D. Griffiths. Addict. Behav. Rep. 12, 100311 (2020) 